\title{
Flexural Behavior of Reinforced Concrete Beams Strengthening with Glass Fiber Reinforced Polymer (GFRP) at Different Sides
}

\author{
Ali Kadhim Sallal ${ }^{1}$, Ancy Rajan ${ }^{2}$ \\ ${ }^{1}$ Department of Applied Mechanics Maharashtra Institute of Technology (MIT) College of Engineering, Pune, India \\ ${ }^{2}$ Professor, Department of Applied Mechanics Maharashtra Institute of Technology (MIT) College of Engineering, Pune, India
}

\begin{abstract}
Strengthening the structural members of old buildings using advanced materials are a contemporary research in the field of repairs and rehabilitation. Many researchers used Glass Fiber Reinforced Polymer (GFRP) sheets for strengthening Reinforced Concrete RC-beams. In this research work, different sizes of Glass Fiber Reinforced Polymer (GFRP) laminates were used for strengthening reinforced concrete beams to achieve higher flexural strength and load carrying capacity. Nine beams will be used in this test with size of $(700 \times 150 \times 150) \mathrm{mm}$; three beams were tested to study the load carrying capacity of control specimens and the others six beams strengthened with Glass Fiber Reinforced Polymer (GFRP) using epoxy resin. Two point bending flexural tests were conducted up to failure on reinforced concrete beams retrofitted and control beams. This paper include study the experimental work on flexural strengthening of Reinforced Concrete (RC) beams using Glass Fiber Reinforced Polymer (GFRP) laminates and the results are compared with each other's.
\end{abstract}

Keywords: Polymer, GFRP, FRP, RC, CFRP, beams, casting

\section{Introduction}

Generally, structures are subjected to natural and man-made loads during their service life. When the magnitude of these loads exceed the capacity of the structures, they are possible to be damaged. Sometimes the strength of a structure is reduced because of the use of sub-standard materials in its construction or due to application the extra load because of change in functioning or due to seismic forces for which the structure had not been designed originally. Engineers are looking for new materialsFiber Reinforced Polymer (FRP) that can be used to extend the service life of existing structures. [3]

\subsection{Fiber Reinforced Polymer (FRP)}

Fiber Reinforced Polymer (FRP) is a relatively composite material manufactured from Fibers and resins and Fiber Reinforced Polymer proven efficient and economical for the repair of new and old structures. The Fibers are usually Glass Fiber, Steel Fiber or Carbon Fiber.[4]The characteristic of Fiber Reinforced Polymer (FRP) includes high resistance to corrosion, impact strength, high strengthto-weight ratio,high tensile and lightweight impact strength, weariness resistance, non-conductive and magnetically neutral. For these reasons, Fiber Reinforced Polymer (FRP) is manufacture for the using in the construction that exposed to truculent environments such as seawater, underground water and frost. As a result, Fiber Reinforced Polymer (FRP) have been successfully used in many construction applications such as chemical treatment plants, under water structures, bridges applications, airport runways and water tanks. [1]

\section{Objective of Study}

The purpose of this research is
- To study the behavior of the reinforced concrete (RC) beams reinforced with Glass Fiber Reinforced Polymer sheets at different sides.

- To understand the failure modes of strengthened and nonstrengthened beams.

- To evaluate the effect of Glass Fiber Reinforced Polymer sheets on the strength and deflection of the strengthened and non-strengthened beams.

\section{Review of Literature}

Flexural Behavior of Reinforced Concrete Beam with Glass Fiber Reinforced Polymer (GFRP) Bar Strengthened with Carbon Fiber Reinforced Polymer (CFRP) Plate. [5](Norhafizah Salle h- Abdul Rahman Mohd.Sam - Jamaludin Mohd Yatim and Mohd - Firdaus Bin Osman)

This paper present the experimental work on the flexural behavior of reinforced concrete (R.C) beams reinforced with Glass Fiber Reinforced Polymer (GFRP) bars and strengthens with Carbon Fiber Reinforced Polymer (CFRP) plate.A total 10 reinforced concrete beams reinforced with either Steel or Glass Fiber Reinforced Polymer (GFRP) bars were cast and tested under 4- point loads. Eightrein forced concrete $($ R.C) beams of size $(200 \times 250 \times 2800) \mathrm{mm}$ were reinforced with $(13 \mathrm{~mm})$ diameter Glass Fiber Reinforced Polymer (GFRP) bars together and strengthening using Carbon Fiber Reinforced Polymer (CFRP) plate and two control beams (un wrapped) reinforced with $(12 \mathrm{~mm})$ diameter steel bars were tested. The experimental results show, although the stiffness of the reinforced concrete (R.C) beams reduced but the ultimate load of the Glass Fiber Reinforced Polymer (GFRP) reinforced concrete beam is bigger than steel reinforced beam. 


\section{International Journal of Science and Research (IJSR) \\ ISSN (Online): 2319-7064 \\ Index Copernicus Value (2013): 6.14 | Impact Factor (2015): 6.391}

\section{Conclusions}

- Use Glass Fiber Reinforced Polymer (GFRP) bars as direct replacement of steel reinforcement in concrete beam was found to decrease the stiffness but higher load carrying capacity compared to the conventional reinforced concrete (R.C) beam. This was due to the lower elastic modulus of the Glass Fiber Reinforced Polymer (GFRP) bars compared to steel.

- Strengthening of the reinforced concrete beam reinforced with Glass Fiber Reinforced Polymer (GFRP) bars using Carbon Fiber Reinforced Polymer (CFRP) plate will improve the flexural behavior of the beams by increase the beam stiffness and ultimate load of the (R.C) beam.

- All the strengthened reinforced concrete beams failed in flexure with the debonding of the Carbon Fiber Reinforced Polymer (CFRP) plate. Beam strengthened using longer Carbon Fiber Reinforced Polymer (CFRP) plate produced better performance compared to shorter plate.

Experimental Investigation of Reinforced Concrete (RC) Flexural Beams Strengthened with Carbon Fiber Reinforced Polymer (CFRP) [6](Prof. Dr. Husain M. Husain* Assist. Prof. Dr. Nazar K. Al-Oukaili** DAWLAT D. $A L I)$

Experimental investigations on the behavior of reinforced concrete beams strengthened by using Carbon Fiber Reinforced Polymer (CFRP) in flexural case have been presented in this paper. The experimental work consisted of 14 test beams. This study took into account strengthened and repaired cases in using Carbon Fiber Reinforced Polymer (CFRP); therefore, similar beams were used for strengthening at one time and for repairing at another time to make a comparison between them. All the reinforced concrete (R.C) beams had been tested in a simply supported span and subjected to two-point loading until the failure. The beams included additional anchorage at the ends of the main Carbon Fiber Reinforced Polymer (CFRP) sheet reinforcement to prevent the delamination of Carbon Fiber Reinforced Polymer (CFRP) sheet. The results of experiments show that the use of Carbon Fiber Reinforced Polymer (CFRP) as external strengthening has significant enhancement on the ultimate load, crack pattern and deflection of the strengthened of beams. It is observed from the workthat the use of external Carbon Fiber Reinforced Polymer (CFRP) in strengthening beams could improve the ultimate load capacity of beam up to $(160 \%)$ over the capacity of the control beam (unwrapped beam).

\section{Conclusions}

- In all cases in the present work (flexural group), the failure in strengthened beams is caused by yielding the steel fallowed by Carbon Fiber Reinforced Polymer (CFRP) rupture.

- The presence of external Carbon Fiber Reinforced Polymer (CFRP) bonded (R.C) beams increases the ultimate load at failure to a significant value. The maximum increase in the ultimate strength of externally strengthened beams by Carbon Fiber Reinforced Polymer (CFRP) depends on the amount of the area and configuration of the external Carbon Fiber Reinforced Polymer (CFRP) sheet added.

- The use of external Carbon Fiber Reinforced Polymer (CFRP) sheet connected to the tension sides of beams could enhance the ultimate load capacity by $(160 \%)$ in flexure over the capacity of the identical unstrengthen control (unwrap) beam.

- Same behavior for strengthened and repaired beams is noticed except that the ultimate load in repaired beams reaches (95\% to $97 \%$ ) of ultimate load of strengthened beams.

\section{Experimental Model}

The main objective of the work is to study the effect of Glass Fiber Reinforced Polymer (GFRP) in improving the flexural behavior of the reinforced concrete beams. This chapter describes the details of test specimens, strengthening system, material properties and test procedure. Detail of beam shown in Figure (1).

\subsection{Description of Specimen}

- Three beams (A1, A2, A3) (1) design as control beam (CB) was not strengthen

- Three beams (B1, B2, B3) (2) were strengthen with 1layers of (E-Glass) laminate of width $(\mathbf{5 6 0} \mathbf{~ m m})$ at bottom without gaps

- Three beams (D1, D2, D3) (4) were strengthen with 1layer of (U-shaped) E-Glass laminate of width $(\mathbf{5 6 0} \mathbf{~ m m})$ without gaps

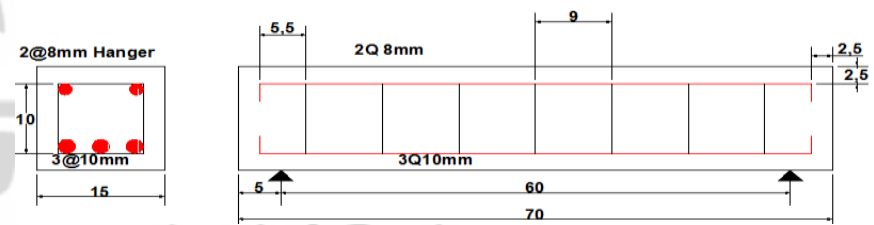

Figure 1: Longitudinal detail of beams and all dimensions in $(\mathrm{mm})$

NU-1 : Without Wrapped ( Control

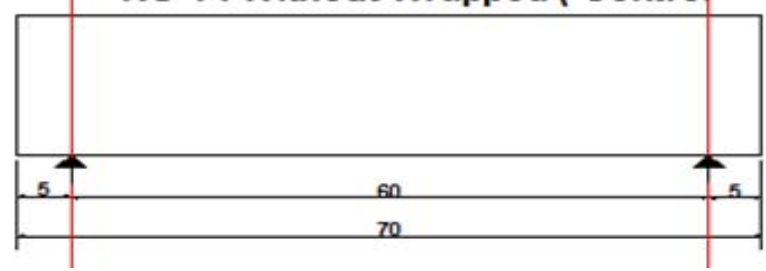

NU-2: Wrapped 1-layer at bottom

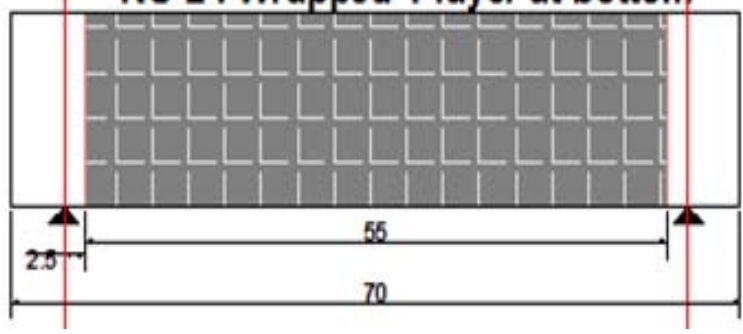




\section{International Journal of Science and Research (IJSR) \\ ISSN (Online): 2319-7064}

Index Copernicus Value (2013): 6.14 | Impact Factor (2015): 6.391

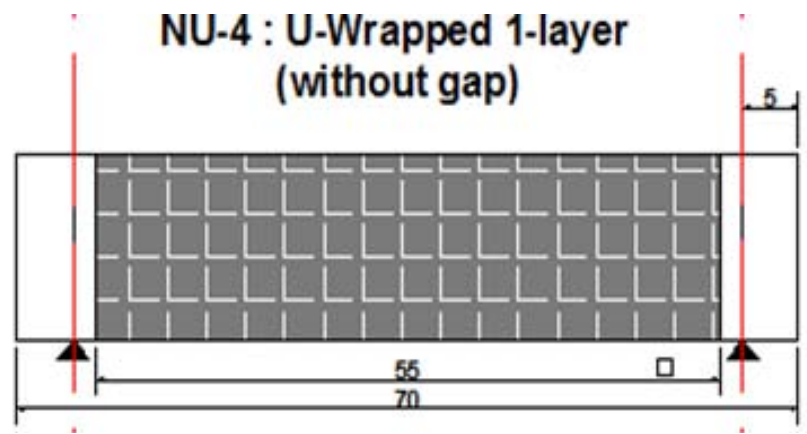

Figure 2: Details of Wrapped Beam

\subsection{Materials for Casting}

\subsubsection{Cement $(C)$}

The type of cement that used in the experimental work was (OPC) of (53) grade

\subsubsection{Fine Aggregate (F.A)}

Locally available crushed sand will use according to (IS 383-1970) [7]

Table 1: Sieve Analysis Results of Fine Aggregate (F.A)

\begin{tabular}{|c|c|c|}
\hline IS Sieve & Percentage of passing & IS limits for zone II \\
\hline $4.75 \mathrm{~mm}$ & 93 & $90-100$ \\
\hline $2.36 \mathrm{~mm}$ & 76.4 & $75-100$ \\
\hline $1.18 \mathrm{~mm}$ & 55.4 & $55-90$ \\
\hline 600 microns & 40.4 & $35-59$ \\
\hline 300 microns & 28.4 & $8-30$ \\
\hline 150 microns & 9.1 & $0-10$ \\
\hline Pan & 0 & - \\
\hline
\end{tabular}

\subsubsection{Coarse Aggregate (C.A)}

Gravel of $(20 \mathrm{~mm})$ and down size will use according to (IS 383-1970)[7]

Table 2: Sieve Analysis Results of Coarse Aggregate (C.A)

\begin{tabular}{|c|c|}
\hline IS Sieve & Percentage of passing \\
\hline $25 \mathrm{~mm}$ & 100 \\
\hline $20 \mathrm{~mm}$ & 99.6 \\
\hline $12.5 \mathrm{~mm}$ & 56 \\
\hline $10 \mathrm{~mm}$ & 16.4 \\
\hline $4.75 \mathrm{~mm}$ & 0 \\
\hline
\end{tabular}

\subsubsection{Concrete}

(M-30) grade of concrete designed as per (I.S 10262-2009) [8] will use in the program

\subsubsection{Water $(W)$}

Water available in the college campus conforming to requirements of water for concreting and curing as per (IS: 456-2000) [9].

\subsubsection{Properties of Steel Reinforcement}

For reinforcement the beams, steel of grade (Fe-415) will use. For the reinforcement in the bottom and top, bars of $(\varnothing 10 \mathrm{~mm})$ and $(\varnothing 8 \mathrm{~mm})$ respectively will use. For stirrups (Ø6 $\mathrm{mm})$ will be use.

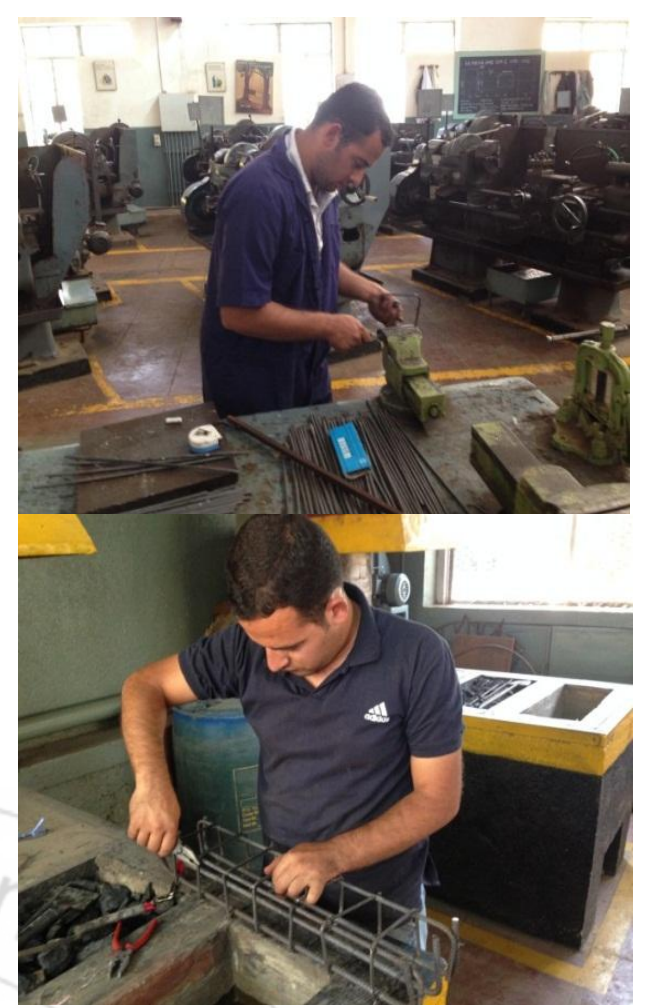

Figure 3: Details of Steel Reinforcement

4.2.7 Glass Fiber Reinforced Polymer (GFRP)

E-glass fiber will be used in this project.

\subsubsection{Primer}

To promote adhesion and prevent the surface from drawing resin from the Fiber Reinforced Polymer (FRP) layer, a low viscosity epoxy primer is applied on beam with a roller until the substrate is saturated fall. The primer was prepared by mixing the base and the hardener in the proportion of (10050) [base: harder], in this proportion was used as per the manufacture recommendation.

\subsubsection{Saturant}

To apply the Glass Fiber Reinforced Polymer (GPRP) laminates on the beams saturant is used. The saturant was mixed in proportion of (10-12) [base: hardener] by weight as recommended by manufacturer.

\subsection{Casting the Beams}

The proportion of (1:1.5:2: 0.4)is taken for Cement, Fine Aggregate (F.A), Course Aggregate (C.A) and Water. The mixing is done by the hands. The beams are cured for $\mathbf{2 8}$ days in the water. For each beam two concrete cube specimens were made at the time of casting and kept in the water also for curing. The uniaxial compressive tests on produced concrete $\left(150 \times 150 \times 150 \mathbf{m m}^{3}\right.$ concrete cube $)$ were performed and the average concrete compressive strength (fcu) after 28 days for each beam. 


\section{International Journal of Science and Research (IJSR) \\ ISSN (Online): 2319-7064}

Index Copernicus Value (2013): 6.14 | Impact Factor (2015): 6.391

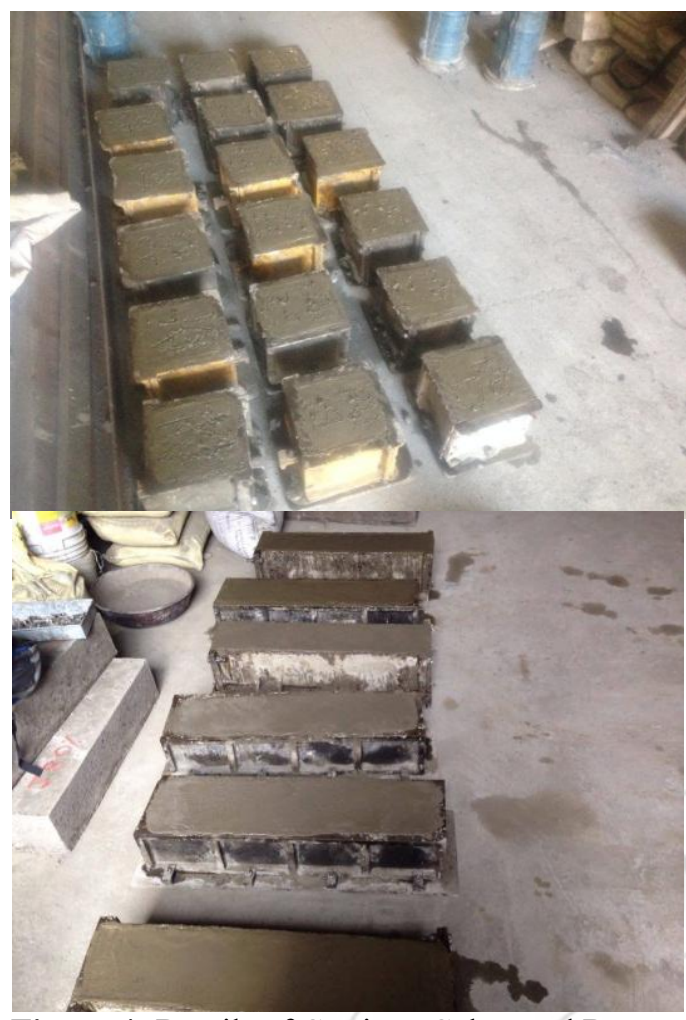

Figure 4: Details of Castings Cubes and Beams

\subsection{Curing of Concrete}

The specimens (beams and cubes) were curried in a basin of water(at room temperature)for (28 days) to prevent the loss of water which is essential for the process of hydration also the curing contribute to increase the strength of concrete.

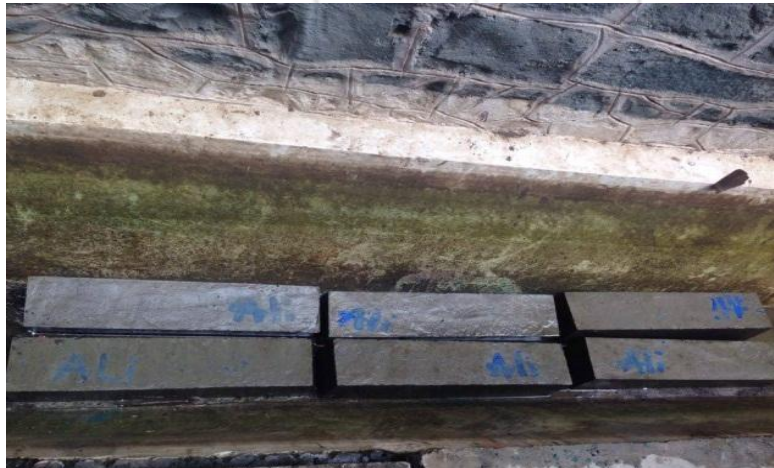

Figure 5: Curing the Specimens in Water for 28 Days

\subsection{Application of (GFRP) Laminates}

The procedure that was used in applying Glass Fiber Reinforced Polymer (GFRP) composite system is summarized below. These steps were followed according to the recommendation of Glass Fiber Reinforced Polymer (GFRP) manufacturer and ACI committee 440 [10].

\subsubsection{Preparation of Concrete Surface}

- Grinding the concrete surface by scraper at the location of gluing the Glass Fiber Reinforced Polymer(GFRP) on the concrete to remove the weak surface.

- Clean and remove the dust from the concrete surface by sand paper.

\subsubsection{Application of Primer}

- Mix the base epoxy resin and the hardener together according to manufacturer technical data by slow speed electrical drill.

- Apply a thin layer of mixed primer on the concrete surface.

\subsubsection{Application of Saturant}

- Mix the base resin and the hardener together according to manufacturer technical data by slow speed electrical drill.

- Apply a thin layer of mixed saturant on the concrete surface after waiting for about 15 minute after application of the primer.

\subsubsection{Application of Glass Fiber Reinforced Polymer (GFRP) laminates}

The pre-wetted or dry fabric is carefully laid on the surface and smoothed out to using steel rollers to remove air bubbles and ensure that the fibers remain straight in alignment. Proper compaction (squeezing of saturant) shall be ensured using roller.

\subsubsection{Curing}

During the cure, 2 to 4 hours depending on ambient conditions, the fabric is checked to ensure that all air bubbles are removed and that the fabric is not sagging.

\subsection{Experimental Works}

All the beams were cast and tested in the department of civil engineering, Maharashtra Institute of Technology (MIT) college, Pune, India.

\subsubsection{Test procedure}

All the beams were painted with black color to observe the cracks were marked with white board pen after each load increment. The beams were tested with load increment of $(20 \mathrm{KN})$ till the failure. The deflection at the mid-span of the beams was recorded at every load increment.

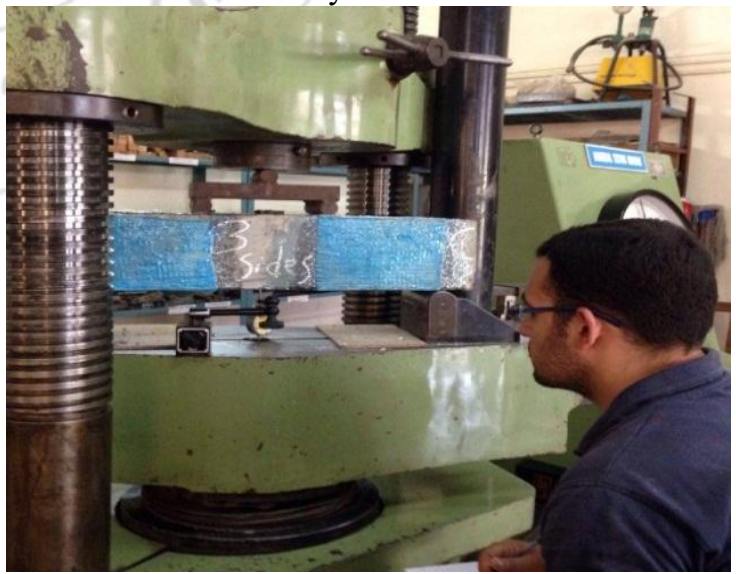

Figure 6: Test set-up for the experimental program

\section{Experimental Results and Discussions}

The objective of the current research work is to investigate the effect of Glass Fiber Reinforced Polymer (GFRP) laminate on the flexural behavior of strengthened and unstrengthened R.C Beams. 


\section{International Journal of Science and Research (IJSR) \\ ISSN (Online): 2319-7064 \\ Index Copernicus Value (2013): 6.14 | Impact Factor (2015): 6.391}

\subsection{Cracking Behaviour}

The first cracking load and cracking pattern observed during the testing are discussed in the following sub section:

\subsection{First Cracking Load}

For control beam-A (without wrapped), first crack was found nearby the mid-span of the beam when the load was increased at about $(86 \mathrm{KN})$. At that moment, the deflection of the beam at the mid-span was recorded as $(2.05 \mathrm{~mm})$.For beam-B was strengthened with 1-layer of (GFRP) at bottom, showed better enhancement in the first diagonal cracking as compared with (control beam A) was found at the left side of the beam when the load was increased at about $(95 \mathrm{KN})$. At that moment, the deflection of the beam at the mid-span was recorded as $(1.05 \mathrm{~mm})$. For beam-D was strengthened with 1-layer of (GFRP) from three sides without gap , showed better enhancement in the first diagonal cracking as compared with (control beam A, strengthened beam B and strengthened beam C) was found when the load was increased at about $(150 \mathrm{kN})$. At that moment, the deflection of the beam near the edge was recorded as $(2.65 \mathrm{~mm})$.

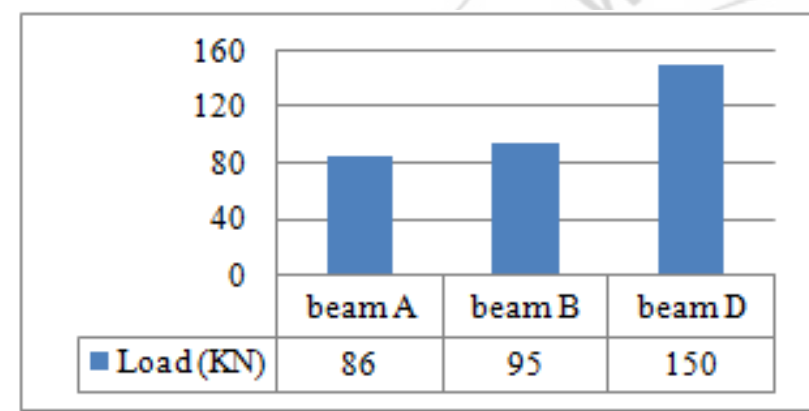

Figure 7: Load at initial crack of all beams

\subsubsection{Beam strengthened with one layer of (GFRP)} laminate at bottom side

The first flexure crack was observed at the left side of the beam near the support when the applied load was $(110 \mathrm{KN})$ also at a load of $(160 \mathrm{KN})$ a new flexure crack occurred at mid-span of the beam. The first shear crack observed on the left side of beam when the load was $(90 \mathrm{KN})$. Further propagation of the crack was checked by the GFRP sheet. At $(98 \mathrm{KN}),(130 \mathrm{KN})$ and $(150 \mathrm{KN})$, shear cracks appeared from the left side of beam near the support.

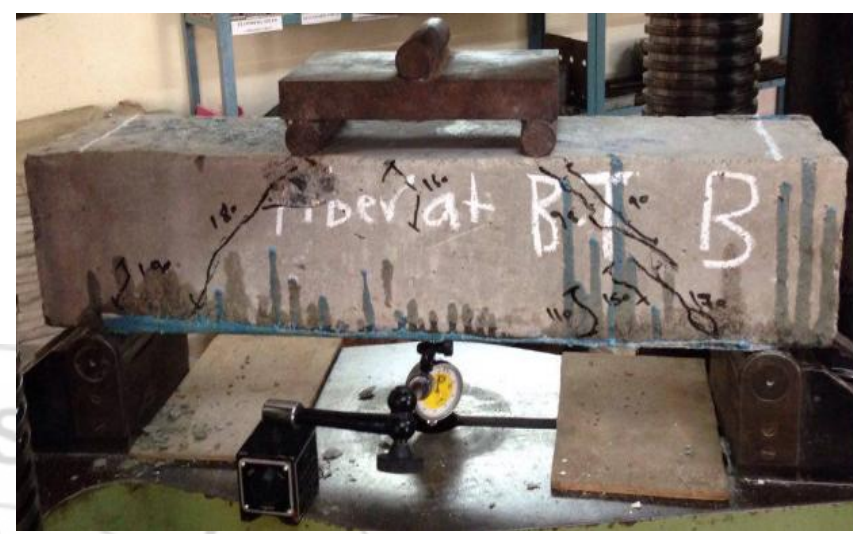

Figure 9: Crack pattern of strengthened Beam-B

\subsubsection{Beam strengthened with one layer of (GFRP)} laminate from three sides without gab

In back side of beam, the first flexure crack was observed at the left side of the beam when the load was $(150 \mathrm{KN})$. With increase in the load, other flexural cracks appeared on the left and right sides of the beam.In front side of beam, the first shear crack appeared when the load was $(97 \mathrm{KN})$ and $(100 \mathrm{KN})$ on the left side of the beam. With increase the load, shear cracks appeared when the load was (120 KN). The directions of these cracks were parallel to the (GFRP) sheet.

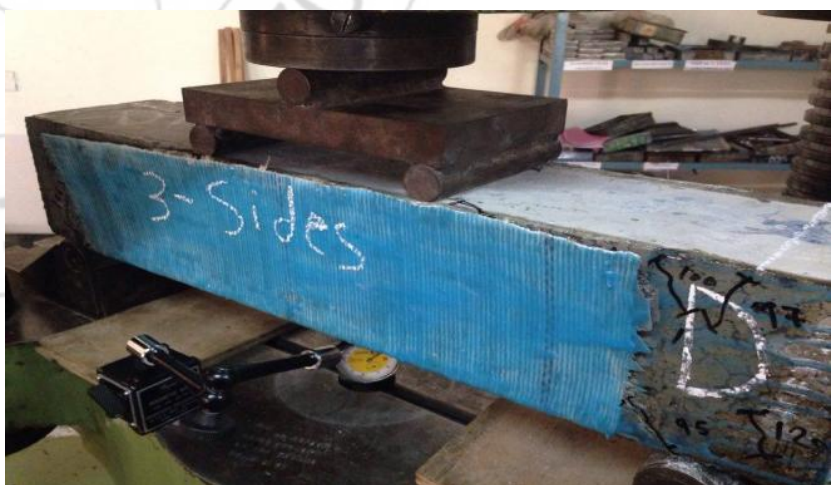

Figure 10: Crack pattern of strengthened Beam-D

\subsection{Deflections}

Nine beam specimens were cast and tested to examine the response of (GFRP) strengthened reinforced concrete beams. All the deflections were measured till the ultimate load.

\subsubsection{Control Beam}

The load deflection curve for (control beam-A) is shown in (Figure 11). The load deflection curve of (control beam -A) is included for the purpose of comparison with strengthened beams. The control beam-A exhibited a linear behavior up to
Figure 8: Crack pattern of Control Beam-A (without wrapped) 


\section{International Journal of Science and Research (IJSR) \\ ISSN (Online): 2319-7064 \\ Index Copernicus Value (2013): 6.14 | Impact Factor (2015): 6.391}

a load of $(160 \mathrm{KN})$ and then there was increase in the value of deflection in the curve. This increase in the value of deflection was due to loss of bond between the concrete and longitudinal steel reinforcement hooks at the support after initiation and rapid progression of the shear cracks which caused sudden failure. The deflection at the ultimate load $(170 \mathrm{KN})$ was $(5.5 \mathrm{~mm})$.

\subsubsection{Beam strengthened with one layer of (GFRP)} laminate at bottom side

The load deflection curve for strengthened (beam-B) with (control beam-A) is shown in (Figure 11). The load deflection curve of this beam compared with (control beamA). The strengthened beam specimen-B exhibited linear behavior up to $(160 \mathrm{KN})$ and then there was increase in value of deflection in the curve. This increase was due to the debonding of the (GFRP) sheet near the support from left side of beam also there was increase in value of deflection in curve at a load of $(180 \mathrm{KN})$ up to the ultimate load also because of the debonding of the (GFRP) sheet. The deflection of strengthened beam at ultimate load of (193 $\mathrm{KN})$ was $(5 \mathrm{~mm})$. The resisting crack growth and also had better load carrying capacity as compared with control beam. As compared with (beam-A), the deflection at ultimate load of beam-A $(170 \mathrm{KN})$ was $(3.2 \mathrm{~mm})$ less than the value of deflection of (beam- A) at ultimate load (4.4 $\mathrm{mm}$ ). (beam-B) consider stronger as compared with control beam.

5.4.3 (Beam-C) strengthened with one layer of (GFRP) laminate from three sides without gab

For strengthened (beam-D) consider stronger as compared with strengthened (beam-B) and (control beam-A). The strengthened (beam-C) exhibited linear behavior up to (170 $\mathrm{KN}$ ) and then the value of deflection increase in the curve. This increase in value was due to the debonding of the (GFRP) sheet at upper two sides (right and left) of the beam near the support also at a load of $(207 \mathrm{KN})$ the value of deflection was $(5.3 \mathrm{~mm})$. The value of deflection at the ultimate load $(260 \mathrm{KN})$ of strengthened (beam-C) was (8 $\mathrm{mm})$.

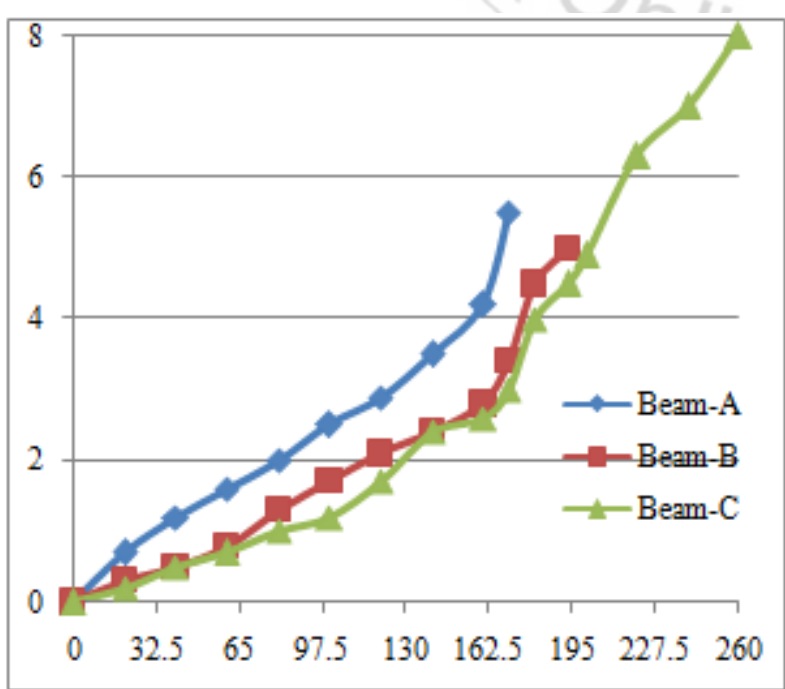

Figure 11: Load - Deflection curve of control Beam-A, Beam-B and Beam-D
Table 3: The value of deflection for (Beam-A, Beam-B, Beam-C) at different value of loads

\begin{tabular}{|c|c|c|c|}
\hline \multirow{2}{*}{ Load (KN) } & \multicolumn{3}{|c|}{ Deflection (mm) } \\
\cline { 2 - 4 } & Beam-A & Beam-B & Beam-D \\
\hline 0 & 0 & 0 & 0 \\
\hline 20 & 0.7 & 0.3 & 0.2 \\
\hline 40 & 1.2 & 0.5 & 0.5 \\
\hline 60 & 1.6 & 0.8 & 0.7 \\
\hline 80 & 2 & 1.3 & 1 \\
\hline 100 & 2.5 & 1.7 & 1.2 \\
\hline 120 & 2.9 & 2.1 & 1.7 \\
\hline 140 & 3.5 & 2.4 & 2.4 \\
\hline 160 & 4.2 & 2.8 & 2.6 \\
\hline 170 & 5.5 & 3.4 & 3 \\
\hline 180 & ------------ & 4.5 & 4 \\
\hline 193 & ------------ & 5 & 4.5 \\
\hline 200 & ------------ & ------------- & 4.9 \\
\hline 207 & ------------ & ------------- & 5.3 \\
\hline 220 & ------------ & -------------- & 6.3 \\
\hline 240 & ------------ & -------------- & 7 \\
\hline 260 & ------------- & -------------- & 8 \\
\hline & & &
\end{tabular}

\section{Conclusions}

The results of this paper that presented an experimental program investigating the flexural behavior of reinforced concrete beams strengthened with GFRP composites laminates at different sides. Based on the experimental results, the following conclusions include:

1) The result of the experimental study indicates that externally bonded GFRP laminates is an effective method to increase the strengthof reinforced concrete beams and improve the structural load carrying capacity.

2) GFRP wrapped reinforced concrete beam was found to be very effective in increasing the load - carrying capacity, deflection and ductility of R.C beams when compared to the (control beam-A).

3) GFRP wrapped reinforced concrete beam-B and beam-D showed an increase in ultimate load carrying capacity by $10.4 \%$ compared to the (control specimen $-\mathrm{A}$ ).

4) GFRP wrapped reinforced concrete beam-B and beam-D showed an increase in ultimate load carrying capacity by $74.4 \%$ compared to the (control specimen $-\mathrm{A}$ ).

\section{References}

[1] TEOH CHIN SIANG, UNIVERSITI TEKNOLOGI MALAYSIA, PSZ 19:16 (Pind. 1/97), BORANG PENGESAHAN STATUS TESIS, [FLEXURAL BEHAVIOR OF CONCRETE BEAM REINFORCED WITH GLASS FIBER REINFORCED POLYMER (GFRP) SECTION], APRIL 2006

[2] NISHIKANT DASH, DEPARTMENT OF CIVIL ENGINEERING NATIONAL INSTITUTE OF TECHNOLOGY ROURKELA-769008, ORISSA INDIA [STRENGTHENING OF REINFORCED CONCRETE BEAMS USING GLASS FIBER REINFORCED COMPOSITES]

[3] Adane Z. Abegaz, [Advanced Fiber Reinforced Composites as Confining Systems for RC Columns] 2013-12-18, University of Miami, adane.zeleke@gmail.com. 
[4] Kinjal V Ranolia, B K Thakkar, J D Rathod,[ Effect of Different Patterns and Cracking in FRP Wrapping on Compressive Strength of Confined Concrete], Available online at www.sciencedirect.com

[5] Norhafizah Salleh, Abdul Rahman Mohd.Sam, Jamaludin Mohd Yatim and Mohd. Firdaus Bin Osman [Flexural Behaviour of Reinforced Concrete Beam with Glass Fiber Reinforced Polymer (GFRP) Bar Strengthened with Carbon Fiber Reinforced Polymer (CFRP) Plate], Advanced Materials Research Vol. 1051 (2014) pp 748-751, Online available since 2014/Oct/27 at www.scientific.net, (c) (2014) Trans Tech Publications, Switzerland, doi:10.4028/www.scientific.net/AMR.1051.748

[6] Prof. Dr. Husain M. Husain, [EXPERIMENTAL INVESTIGATION OF REINFORCED CONCRETE FLEXURAL BEAMS STRENGTHENED OR REPAIRED WITH CFRP], Building and Construction Department/ University of Technology, College of Engineering/University of Baghdad, Volume 15 September 2009, Journal of Engineering.

[7] IS 383:1970, Indian Standard [SPECIFICATION FOR COARSE AND FINE AGGREGATES FROM NATURAL SOURCES FOR CONCRETE] (Second Revision)

[8] IS 10262: 2009, Indian Standard [CONCRETE MIX PROPORTIONING - GUIDELINES (First Revision)]

[9] IS 456: 2000, Indian Standard [PLAIN AND REINFORCED CONCRETE CODE OF PRACTICE].

[10]ACI 440.1R-06, [Guide for the Design and Construction of Structural Concrete Reinforced with FRP Bars] 